\title{
Macroevolution of sexual size dimorphism and reproduction-related phenotypic traits in lizards of the Chaco Domain
}

\author{
Guadalupe López Juri* Đi, Margarita Chiaraviglio and Gabriela Cardozo
}

\begin{abstract}
Background: Comparing sexual size dimorphism (SSD) in the light of the phylogenetic hypothesis may help to understand the phenotypic evolution associated with sexual selection (size of whole body and of reproductionrelated body parts). Within a macroevolutionary framework, we evaluated the association between the evolution of SSD and the evolution of reproduction-related phenotypic traits, and whether this association has favored female fecundity, considering also variations according to reproductive modes. We focused on the lizard species that inhabit the Chaco Domain since this is a natural unit with a high diversity of species.

Results: The residual SSD was related positively with the residuals of the reproduction-related phenotypic traits that estimate intrasexual selection and with the residuals of inter-limb length and, according to fecundity selection, those residuals were related positively with the residuals of clutch size in oviparous species. Lizards of the Chaco Domain present a high diversity of SSD patterns, probably related to the evolution of reproductive strategies.

Conclusions: Our findings highlight that the sexual selection may have acted on the whole-body size as well as on the size of body parts related to reproduction. Male and female phenotypes evolutionarily respond to variations in SSD, and an understanding of these patterns is essential for elucidating the processes shaping sexual phenotype diversity from a macroevolutionary perspective.
\end{abstract}

Keywords: Sexual size dimorphism, Macroevolution, Intrasexual selection, Fecundity selection, Reproductive mode, Chaco Domain

\section{Background}

Sexual size dimorphism (SSD) is generally related to way in which each sex gets the reproductive success $[1,2]$. The body size associated with maximum fitness (i.e. the optimal body size) thus often differs between the sexes [3]. From a macroevolutionary perspective in terms of $\mathrm{SSD}$, it is interesting to analyze the magnitude and the direction of the evolutionary dynamics of male and female phenotypes. Comparing species phenotypes, considering sexual differences, in the light of the phylogenetic hypothesis will contribute to understanding the evolutionary relationships associated with sexual selection.

\footnotetext{
* Correspondence: lopezjguada@hotmail.com

Laboratorio de Biología del Comportamiento; Instituto de Diversidad y Ecología Animal (IDEA), CONICET-UNC and Facultad de Ciencias Exactas, Físicas y Naturales, Universidad Nacional de Córdoba, X5000JJC. Av. Vélez Sársfield 299, Córdoba, Argentina
}

Since the magnitude of sexual dimorphism is an emergent property that varies depending on the body size of the sexes, one main goal from an evolutionary perspective is to elucidate whether sexual dimorphism is also dependent on species size. According to Rensch's rule, when males are the larger sex, SSD increases with increasing body size (hyperallometry; [4]); conversely when females are the larger sex, SSD decreases with increasing body size (hypoallometry; [5]). The body size of an animal is a key ecological and evolutionary trait for the species, evolving towards an optimum, depending on the ecological contexts and reproductive strategies [6, 7]. Therefore, the evolution of different strategies between the sexes and the consequent variations in the direction and magnitude of sexual size dimorphism may be related to species-specific body size.

Evolutionary hypotheses have been proposed for SSD changes in Squamata. Cox et al. [8] defined: 1) 
Intrasexual Selection Hypothesis: the strength of sexual selection diverts body size towards males, for large male size, which confers an advantage in intrasexual mate competition; and 2) Fecundity Advantage Hypothesis: the strength of sexual selection diverts body size towards females, for large female size, which confers a fecundity advantage. Evolutionary changes in clutch/litter size seem to be generally accompanied by the predicted interspecific shifts in SSD [8]. However, correlations between evolutionary changes in body size and changes in reproduction-related phenotypic traits (morphological traits involved in reproduction) that contribute to male-male competition or female fecundity have rarely been investigated empirically.

Lizards can present sexual dimorphism in the whole-body size [9] as well as in the relative size of reproduction-related body parts involved in behaviors such as mate competition, courtship and copula (e.g., head, abdomen, tail and limbs), and this can be very informative about the selective pressures imposed [10-12]. Sexual dimorphism in different morphological traits of males and females, related to reproduction, has been interpreted as a product of differential pressures between the sexes [13]. In fact, Cardozo et al. [14] suggested that different selective pressures might act on each sex, shaping the morphological traits as sexually dimorphic.

In the context of Intrasexual Selection, male-biased SSD species are expected to present a hyperallometric growth of structures used for aggressive agonistic encounters with other males $[4,8]$. Increased male head size may be important in aggressive interactions, since it has been associated with bite force used during combat [15-18]. Size of hind limbs may be important, because muscle mass may help males to run at high speed [19] and consequently to dominate in combat over territories $[20,21]$. However, reproduction-related phenotypic traits may be simultaneously important in intersexual interactions [22] and in intrasexual interactions [15, 23, 24], e.g., head size is an advantageous feature during mating as a signal of quality for females. Similarly, the size of the extremities may also be important for the success of copula, being involved in subjection of the female [25, 26]. The tail may be used both in courtship and/or for defense of the territory [27-29]. Consequently, we predict an association between the evolution of the sexual dimorphism of male-biased SSD species and the evolution of morphological traits such as the size of the head, hind limbs and tail.

From the perspective of Fecundity Advantage Selection, female-biased SSD species are expected to present hyperallometric growth of structures related to reproductive investment. The volume of the body can determine the physical limit to reproduction, i.e., a large body cavity allows females to store larger energy reserves or develop eggs/embryos [14, 30-32]. Consequently, a large trunk length or a greater abdominal perimeter would give the females higher fecundity [33-36]. Furthermore, Cardozo et al. [14] show that, in female lizards, the tail perimeter is positively related with body condition and consequently with stores of energy reserves to reproduction. In relation to the reproductive mode, viviparous females would require larger abdominal cavity than oviparous females because of having longer gestation period [36-38]. Viviparous females may retain the eggs within the uterus or present different degrees of placentation [39], in any case, embryos are retained to an advanced development $[40,41]$. We hypothesize an association between the evolution of sexual dimorphism in female-biased SSD species and the evolution of morphological traits such as trunk length, abdomen width and tail perimeter. We also expect that this association will be different between the reproductive modes.

From a macroevolutionary perspective, several studies in lizard families show that the majority of males are larger than females, although female-biased SSD is common and occurs in nearly every family. Moreover, male-biased SSD reaches extremes in which males are an average $50 \%$ longer than females. In female-biased SSD, in contrast, females may exceed males by as much as $20 \%$. Most families show consistent patterns of male-biased SSD, but some exhibit considerable variation with no clear directional trend in SSD [3].

In the present study, we examined how the lizard species of the Chaco Domain evolved in relationship to patterns of SSD. The Chaco Domain is a natural unit in which the inhabitant species share common patterns and processes. The domain is a homogenous unit with common features of panbiogeography, endemics and cladistic biogeography [42, 43]. This perspective is important for the present study because the processes of evolutionary dynamics that shape the diversity of phenotypes depend on the geographical aspects of the domains $[44,45]$. The Chaco Domain is an important ecologicalevolutionary scenario with a high diversity of species with a variety of ecological strategies [46-48] which is interesting for studying variations in the macroevolutionary patterns of sexual dimorphism in lizards.

Within a phylogenetic comparative framework, we hypothesize that the macroevolutionary dynamics of SSD is related to evolutionary changes of species' body size and reproduction-related phenotypic traits, which, in the case of females, may lead to variation in fecundity. Furthermore, we hypothesize that SSD patterns and the exacerbation of reproduction-related phenotypic traits differ between reproductive modes of the species (see Fig. 1). Therefore, this study aims to: i) Evaluate the magnitude and direction of SSD in lizard species of the Chaco Domain, and analyze the way in which SSD is 


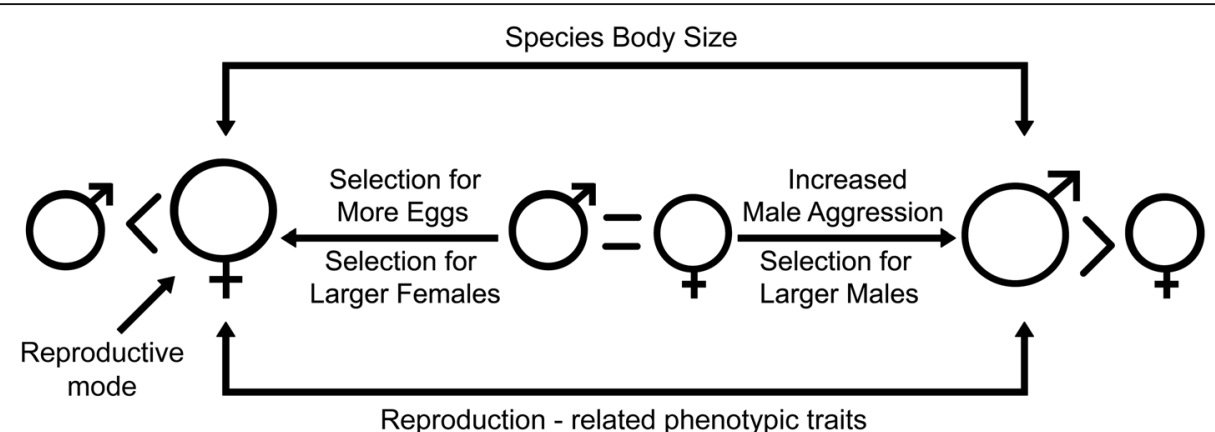

Reproduction - related phenotypic traits

Fig. 1 Schema of our hypothesis of evolution of sexual size dimorphism (SSD) in relation to reproduction-related phenotypic traits, reproductive mode and body size of species in the Chaco Domain (Modified from Corl et al. [82])

related to body size in the species; ii) Evaluate the association between the evolution of SSD and the evolution of reproduction-related phenotypic traits; iii) Evaluate whether SSD and the exacerbation of reproduction-related phenotypic traits have favored female fecundity; iv) Evaluate the magnitude of SSD and the exacerbation of reproduction-related phenotypic traits between reproductive modes.

\section{Methods}

\section{Study area}

The Chaco Domain includes two disjunct areas: the first being the Caatinga region in northeastern Brazil, and the second area comprising sectors east of the Andes mountain range, southern Brazil, southeastern Bolivia, the west and center of Paraguay, much of Uruguay, and the north and center of Argentina. Our study is located in the second area, covering species belonging to the north and center of Argentina. The weather is continental, with moderate to sparse rainfall, mild winters and warm summers. The Chaco harbors an important number of species whose distributions are mostly contained within this region [49].

\section{Species}

We used museum specimens deposited in the Instituto de Herpetología of the Fundación Miguel Lillo, Tucumán, Argentina, the Museo Argentino de Ciencias Naturales Bernardino Rivadavia (MACN), Buenos Aires, the collection of the Instituto de Bio y Geociencias del NOA (IBIGEO - CONICET), and the collection of the Instituto de Diversidad y Ecología Animal (IDEA) CONICET-UNC.

We included all the families of each infraorder of the lizard species (with the exception of Polychrotidae because it was not logistically available) and, within each family, we studied the following genera: Family Liolamidae: Liolaemus, Phymaturus; Family Leiosauridae: Pristidactylus, Diplolaemus, Urostrophus; Family Tropiduridae: Tropidurus, Stenocercus; Family Gymnophthalmidae: Cercosaura, Proctoporus; Family Teidae: Aurivela,
Contomastix, Ameiva, Teius; Family Scincidae: Notomabuya, Aspronema; Family Phyllodactylidae: Phyllopezus, Homonota; 39 species were analyzed: 25 oviparous and 14 viviparous. The 577 individuals corresponded to the larger third (considering snout vent length) of the samples for each species [50], and so we are confident that only adult specimens were considered. For each species, we used an $\mathrm{N}$ minimum of 5 individuals for each sex. In the species presenting strong sexual dichromatism or clear dimorphic external traits, these features were used as diagnostics for sexing individuals. In those species in which external dimorphism is not recognizable, we dissected the specimens and checked gonadal structures to sex individuals.

\section{Traits measured}

Several traits of external morphology were studied in each individual: snout-vent length (SVL), head width (HW), head height $(\mathrm{HH})$, trunk length (TL), abdominal width (AW), tail perimeter (TP) and total length of hindlimb (LH) (Fig. 2). The TP was measured using the centimeter-around-tail circumference and all the other traits were measured from photographs. The photographic record was analyzed with the image software Image J v.1.47 (NIH, USA). Each photo was scaled in reference to a millimeter paper and each measure of the external morphological traits mentioned was registered in triplicate.

To determine potential clutch/litter size, we dissected females corresponding to their reproductive period and quantified the vitellogenic follicles, eggs or embryos. The follicles were considered vitellogenic when they were yellow, dense and opaque inside $[51,52]$.

\section{Phylogenetic framework}

The basic phylogeny used consisted of a reduced phylogenetic tree, built respecting the topologies of the species, according to the hypothesis of the most recent relationships available [53-57]. The Felsenstein criterion was used, assuming a length of branches equal to one for the whole tree, because there was no information 


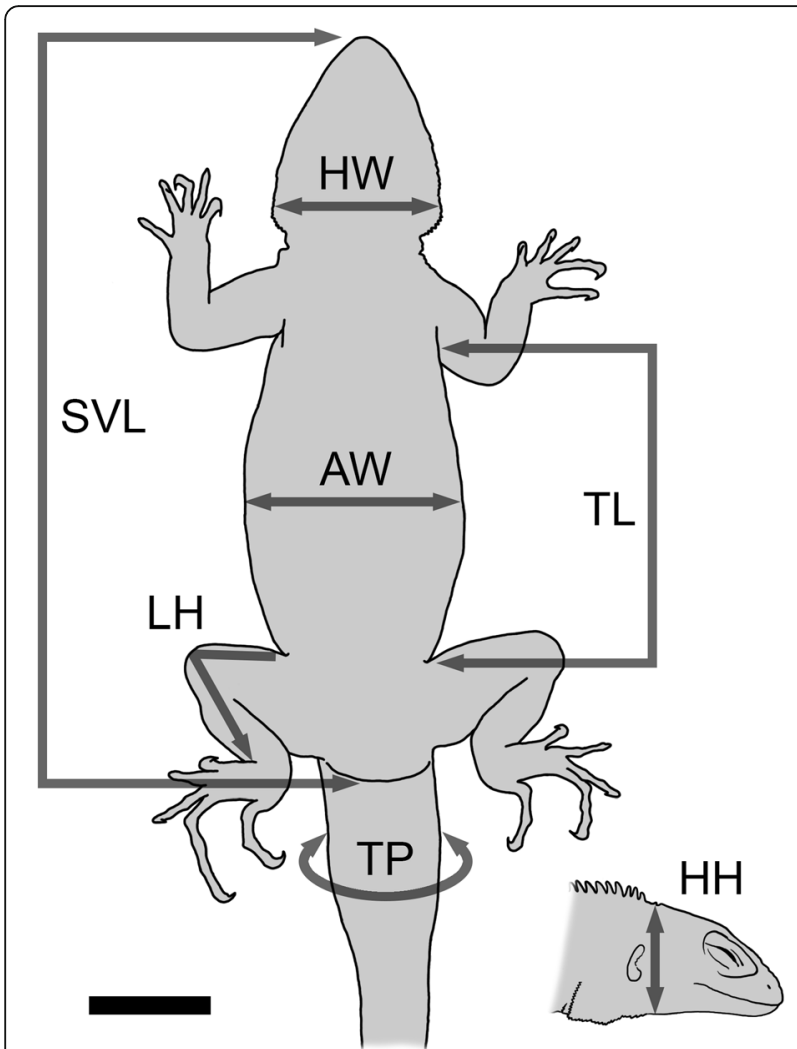

Fig. 2 Traits of external morphology measured in each individual

available on the length of branches in many of these phylogenies [58]. Figure 3 shows the reduced phylogenetic hypothesis of the species included.

\section{Statistical analyses}

For each species, we quantified SSD with the Gibbons and Lovich index [59], SSD (Sexual Size Dimorphism) $=(\mathrm{SVL}$ of longest sex $/ \mathrm{SVL}$ of shortest sex $)-1$. The resulting value is then made negative if males are the larger sex and positive if females are the larger sex [3]. To evaluate the direction and magnitude of sexual dimorphism, a permutations test was performed on SSD, with $p$-value $<0.05$, to determine if the sexual dimorphism index of each species was statistically significant. Those species that equaled or exceeded 15\% of the SSD Index of their own family were also considered dimorphic, despite not having a significant $\mathrm{p}$-value in the permutation test. We categorized the species into 3 SSD groups: male-biased SSD (when sexual dimorphism was deviated towards males); female-biased SSD (when sexual dimorphism was deviated towards females) and monomorphic (when they had no marked sexual dimorphism).

We calculated the mean values of the morphological variables per species per sex and we used Kolmogorov-Smirnov (KS) tests to ensure normality. The variables without normal distribution were

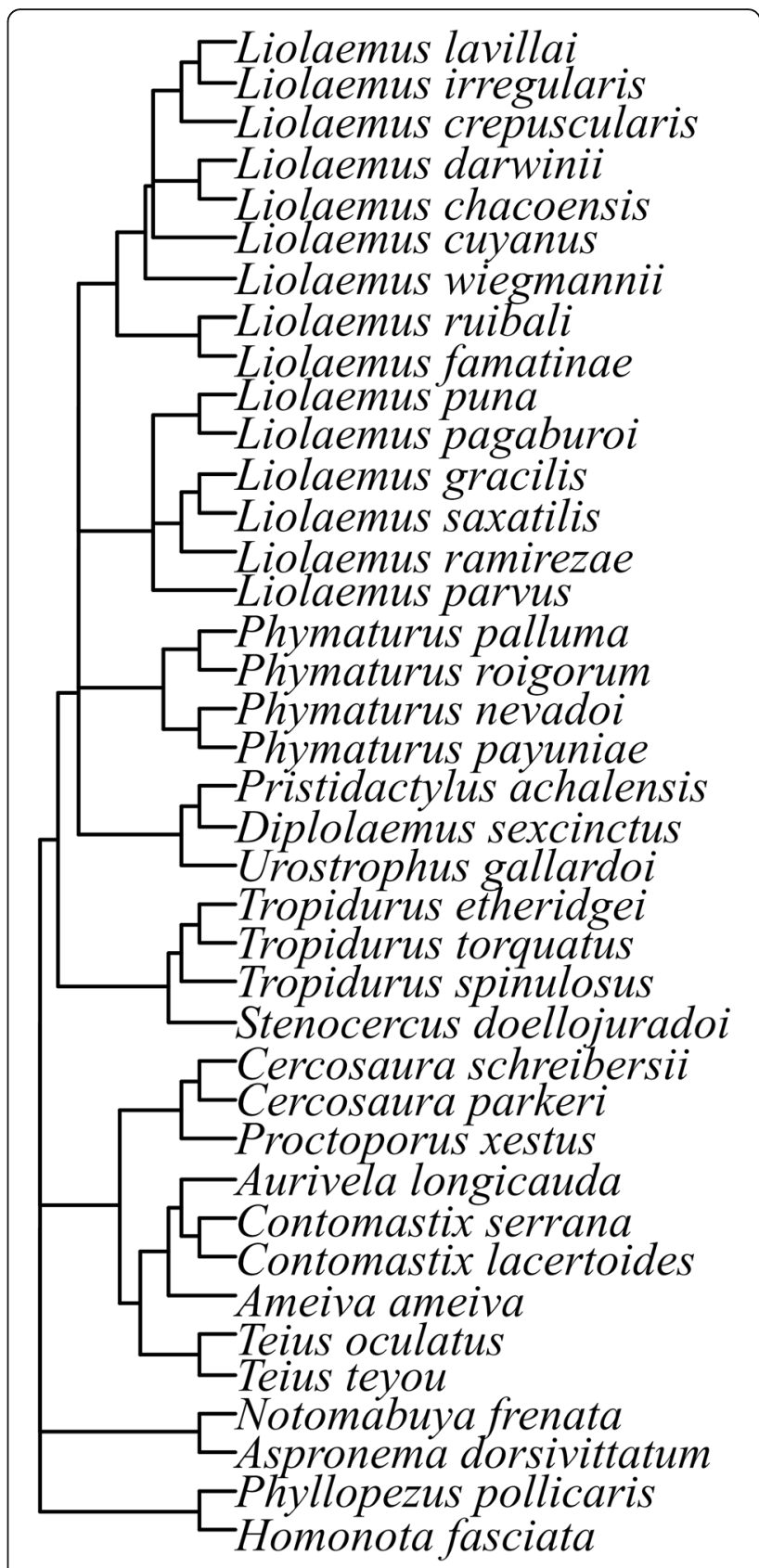

Fig. 3 Phylogenetic hypothesis for the species of the Chaco Domain included in the study. This reconstruction was based on [53-57]

logarithmically $\left(\log _{10}\right)$ transformed priori to analysis. As an estimate of intrasexual selection of reproduction-related phenotypic traits, we calculated an Index sexual dimorphism to $\mathrm{HW}, \mathrm{HH}, \mathrm{LH}$ and $\mathrm{TP}_{\text {male, }}$ as the ratio of $\mathrm{HW}$ in males to $\mathrm{HW}$ in females (IHW $=\mathrm{HW}_{\text {males }} / \mathrm{HW}_{\text {females }}$ ) (see [17, 60, 61]), and the same for the other variables. To estimate the fecundity selection of reproduction-related phenotypic traits, we calculated an Index sexual dimorphism to $\mathrm{TL}, \mathrm{AW}$ and $\mathrm{TP}_{\text {female, as the ratio of } \mathrm{TL} \text { in females }}$ 
to $\mathrm{TL}$ in males (ITL $=\mathrm{TL}_{\text {females }} / \mathrm{TL}_{\text {males }}$ ), and the same for the other variables.

When examining data from phylogenetically related species, data points cannot be considered as statistically independent due to shared evolutionary history $[58,62]$. So we performed the phylogenetic size-correction analysis [63] by using phylo.resid (a module of Phytools for R developed by Revell [64]), over SSD, IHW, IHH, ILH, ITP $_{\text {male }}$, ITL, IAW, ITP female and clutch/litter size. The resultant residuals from the phylogenetic size-correction were then used in the subsequent analyses.

To analyze the relationship between SSD and body size of the species, we ran Phylogenetic Generalized Least Squares (PGLS) using a model with SVLLog 10 as predictor variable and SSD as dependent variable. To analyze the effect of sexual dimorphism on reproduction-related phenotypic traits, PGLS was run using models with resid-

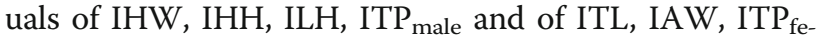
male as dependent variables and the residual SSD and SSD groups (males-biased SSD, females-biased SSD and monomorphic) as predictor variables.

To analyze the effect of sexual dimorphism and female reproduction-related phenotypic traits (only those significantly related to residual SSD according to the previous PGLS) on fecundity, we ran PGLS using models with residual clutch/litter size as the dependent variable and the residual SSD and SSD groups (males-biased SSD, females-biased SSD) as predictor variables. We also ran PGLS using models with residual clutch/litter size as the dependent variable and the residual ITL and SSD groups (males-biased SSD, females-biased SSD) as predictor variables. In these analyses, we eliminated the monomorphic species group because there was not enough data.

To analyze the effect of sexual dimorphism on female reproduction-related phenotypic traits (only those significantly related to residual SSD according to the previous PGLS) considering the species' reproductive mode, we ran PGLS using models with the residual ITL as dependent variable and the residual of SSD and the reproductive mode (oviparous and viviparous) as predictor variables. Also, to analyze the effect of female reproduction-related phenotypic traits of (only those significantly related to residual SSD according to the previous PGLS) on fecundity, we ran PGLS using models with the residual clutch/litter size as dependent variable and the residual of ITL and the reproductive mode (oviparous and viviparous) as predictor variables.

We estimated Pagel's phylogenetic signal $(\lambda)$ from the residual errors simultaneously on the regression parameters of phylogenetic generalized least squares models (PGLS) analyses. Analyses were made in 'caper' [65] and 'ape' [66] packages, both developed in R [67].

\section{Results}

Magnitude and direction of SSD in lizard species of the Chaco Domain

Our results showed that $41 \%$ of the species $(N=16)$ presented male-biased SSD, 41\% $(\mathrm{N}=16)$ female-biased SSD and $18 \%(N=7)$ were monomorphic (Fig. 4). Within each family, sexual dimorphism was not consistent, since most showed both male-biased and femalebiased SSD. The magnitude of the index of sexual dimorphism in species with male-biased SSD was up to -0.33 , and in species with female-biased SSD, it reached 0.30 .

SSD was significantly related to the body size of the species (Adj. $\mathrm{r}^{2}=0.35, p<0.0001$ ), being female-biased in species with small SVL, and male-biased in species with large SVL (Fig. 5).

\section{SSD in relation to reproduction-related phenotypic traits as estimators of intrasexual selection and fecundity selection}

The residual SSD was positively related with the residuals of the reproduction-related phenotypic traits that estimate intrasexual selection in both male- and female-biased SSD species (Table 1). However, there were no differences between the female-biased SSD species and male-biased SSD species in investment in these characters. The residual SSD was positively related only with the residual ITL in female-biased SSD species (Table 1).

\section{Relation between SSD, estimators of fecundity selection and clutch/litter size}

The residual SSD was positively related with the residual clutch/litter size in female-biased SSD species (Table 2). Considering that the only estimator of fecundity related to residual SSD was ITL, we tested the effect of ITL on clutch/litter size. The residual ITL was positively related with residual clutch/litter size in female-biased SSD species (Table 3).

\section{SSD in relation to reproductive modes}

The frequency of female-biased SSD, male-biased SSD and monomorphic species was similar between viviparous and oviparous species (Oviparous: SSD-female: 0.48, SSD-male: 0.36, monomorphic: 0.16; Viviparous: SSD-female: 0.36 , SSD-male: 0.43 , monomorphic: 0.21; $\mathrm{X}^{2}=0.57, p=0.7512$ ).

There was no significant difference in SSD between the reproductive modes (Oviparous: Mean $\mathrm{SSD} \pm \mathrm{SD}$ $=0.01 \pm 0.13$, Viviparous: Mean $\mathrm{SSD} \pm \mathrm{SD}=0.01 \pm$ $0.09, T=-0.49 ; p=0.6239)$. However, in oviparous species SSD ranged from 0.15 to -0.30 , while in viviparous species it varied between 0.30 and -0.15 .

As mentioned above, considering that the sole estimator of fecundity related to residual SSD was ITL, we 

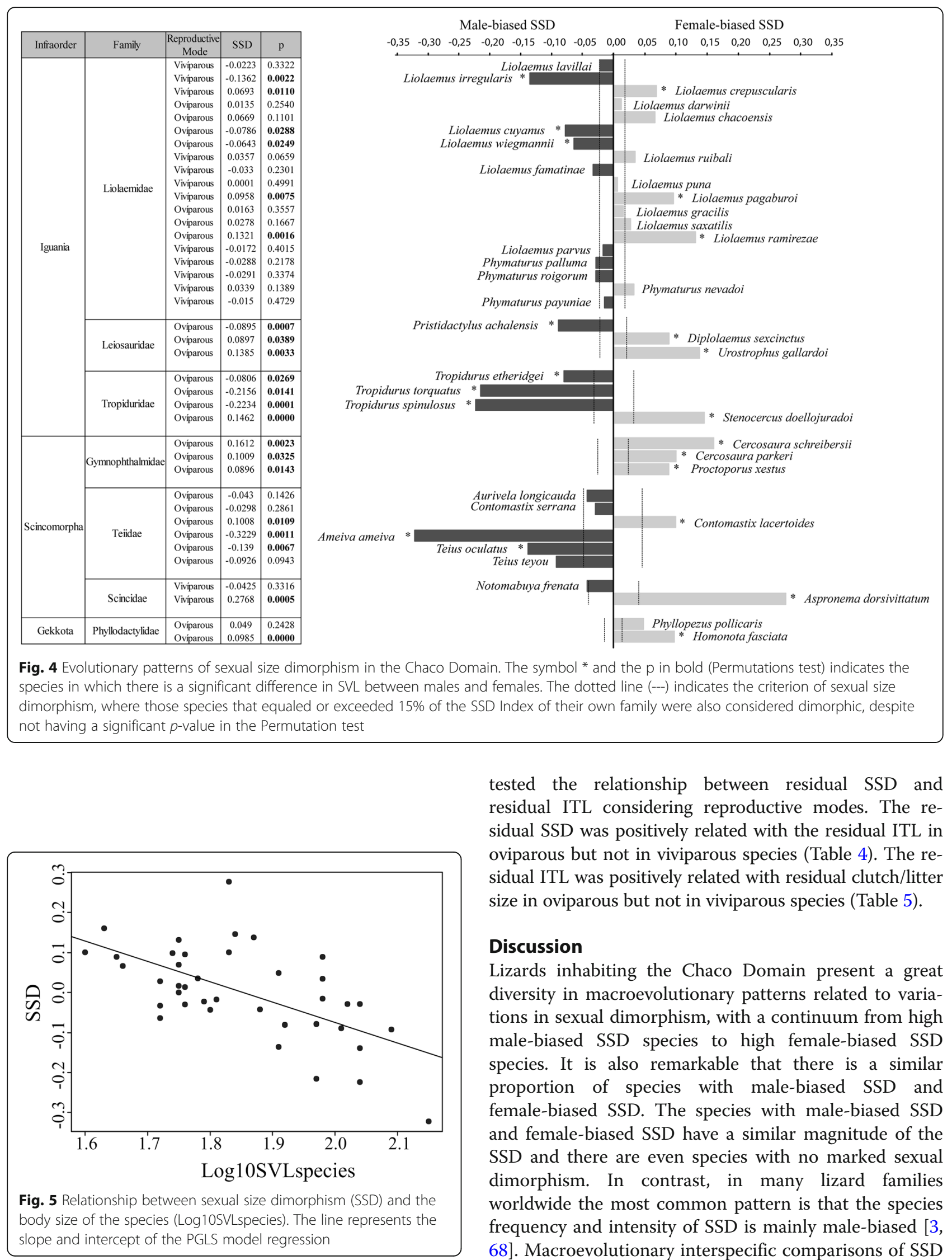

tested the relationship between residual SSD and residual ITL considering reproductive modes. The residual SSD was positively related with the residual ITL in oviparous but not in viviparous species (Table 4). The residual ITL was positively related with residual clutch/litter size in oviparous but not in viviparous species (Table 5).

\section{Discussion}

Lizards inhabiting the Chaco Domain present a great diversity in macroevolutionary patterns related to variations in sexual dimorphism, with a continuum from high male-biased SSD species to high female-biased SSD species. It is also remarkable that there is a similar proportion of species with male-biased SSD and female-biased SSD. The species with male-biased SSD and female-biased SSD have a similar magnitude of the SSD and there are even species with no marked sexual dimorphism. In contrast, in many lizard families worldwide the most common pattern is that the species frequency and intensity of SSD is mainly male-biased [3, 68]. Macroevolutionary interspecific comparisons of SSD 
Table 1 Phylogenetic generalized least squares evaluating the effect of residual SSD on the residuals of the reproduction-related phenotypic traits in the context of intrasexual selection (IHW, IHH, ILH, ITP male) and in the context of fecundity selection (ITL, IAW, ITP female)

\begin{tabular}{|c|c|c|c|c|c|c|}
\hline Model & $\lambda$ & Adj. r 2 & Factor Levels & Slope & SE & $P$ \\
\hline \multicolumn{7}{|l|}{ Intrasexual selection } \\
\hline & & & SSD-female & 0.998 & 0.058 & $<0.001$ \\
\hline Residual IHW & 0.000 & 0.950 & SSD-male & 1.056 & 0.087 & 0.017 \\
\hline \multirow[t]{2}{*}{ Residual SSD } & & & Monomorphic & 1.018 & 0.149 & 0.415 \\
\hline & & & SSD-female & 1.044 & 0.079 & $<0.001$ \\
\hline Residual IHH & 0.000 & 0.922 & SSD-male & 1.047 & 0.120 & $<0.001$ \\
\hline \multirow[t]{2}{*}{ Residual SSD } & & & Monomorphic & 0.980 & 0.205 & 0.055 \\
\hline & & & SSD-female & 0.961 & 0.079 & $<0.001$ \\
\hline Residual ILH & 0.000 & 0.910 & SSD-male & 1.057 & 0.119 & 0.041 \\
\hline \multirow[t]{2}{*}{ Residual SSD } & & & Monomorphic & 1.124 & 0.204 & 0.296 \\
\hline & & & SSD-female & 0.962 & 0.064 & $<0.001$ \\
\hline Residual ITP male $~$ & 0.000 & 0.944 & SSD-male & 1.082 & 0.096 & $<0.001$ \\
\hline Residual SSD & & & Monomorphic & 0.913 & 0.165 & 0.044 \\
\hline \multicolumn{7}{|l|}{ Fecundity selection } \\
\hline & & & SSD-female & 0.934 & 0.057 & $<0.001$ \\
\hline Residual ITL & 0.234 & 0.938 & SSD-male & 0.929 & 0.085 & 0.2436 \\
\hline \multirow[t]{2}{*}{ Residual SSD } & & & Monomorphic & 0.881 & 0.138 & 0.4 \\
\hline & & & SSD-female & 0.204 & 0.307 & 0.51 \\
\hline Residual IAW & 1 & 0.139 & SSD-male & -0.439 & 0.395 & 0.731 \\
\hline \multirow[t]{2}{*}{ Residual SSD } & & & Monomorphic & 1.653 & 1.507 & 0.765 \\
\hline & & & SSD-female & -0.02 & 0.346 & 0.9536 \\
\hline Residual ITP female $~$ & 0.933 & 0.195 & SSD-male & -0.581 & 0.444 & 0.7686 \\
\hline Residual SSD & & & Monomorphic & 1.729 & 1.679 & 0.9728 \\
\hline
\end{tabular}

$\lambda$ phylogenetic signal (Pagel's), $r^{2}$ correlation coefficient, SE standard error

help to understand the diversity of evolutionary patterns of sexual dimorphism across taxa. The high diversity of sexual dimorphism found in the Chaco Domain reveals it as a unit rich in evolutionary dynamics that shape the diversity of phenotypes.

The SSD pattern in the Chaco Domain supports the macroevolutionary pattern commonly named as Rensch's rule $[4,69]$. The body size of the species was related to their SSD: in species of small body size, SSD was commonly female-biased, while in large body size species, SSD was commonly male-biased. While much is known about these evolutionary patterns, it is still a challenge to elucidate the way in which entire phenotypes vary in accordance with SSD variations. Some of our results may help to explain whether body size in SSD-male species is related to increases in body parts involved in male competition or mate acquisition, and if body size in SSD-female species is related to increases in body parts that may be involved in fecundity.

Our results support intrasexual selection based on relationships between residual SSD and residuals of some reproduction-related phenotypic traits of males. The species that invested more in SSD, invested more in the exacerbation of these phenotypic traits, indicating that SSD evolves together with specific body parts, such as the head, limbs or tail. In the case of male-biased SSD lizards male body size is very important since it correlates with measures of reproductive success [70, 71]. Moreover, male body size is correlated with the size of specific body parts. For example, the allometry of head size may be favored by

Table 2 Phylogenetic generalized least squares evaluating the effect of residual SSD on fecundity in SSD groups

\begin{tabular}{llllll}
\hline Model & $\lambda$ & Adj. ${ }^{2}$ & Factor Levels & Slope & SE \\
\hline Residual Clutch/litter size $\sim$ & 1.000 & 0.862 & SSD-female & 1.077 & 0.441 \\
Residual SSD & & SSD-male & 0.920 & 0.037 \\
\hline
\end{tabular}

$\lambda$ phylogenetic signal (Pagel's), $r^{2}$ correlation coefficient, SE standard error 
Table 3 Phylogenetic generalized least squares evaluating the effect of residual ITL on fecundity in SSD groups

\begin{tabular}{|c|c|c|c|c|c|c|}
\hline Model & $\lambda$ & Adj. $r^{2}$ & Factor Levels & Slope & SE & $P$ \\
\hline Residual Clutch/litter size $\sim$ & 1.000 & 0.907 & SSD-female & 1.394 & 0.390 & 0.006 \\
\hline Residual ITL & & & SSD-male & 1.010 & 0.412 & 0.078 \\
\hline
\end{tabular}

$\lambda$ phylogenetic signal (Pagel's), $r^{2}$ correlation coefficient, SE standard error

an advantage in male-male combats or a greater likelihood to be chosen by females $[15,21,72-74]$.

Lizards in which a female-biased SSD prevails may reveal allometry of male reproduction-related phenotypic traits as a product of intersexual interaction. In female-biased SSD species, the more the females of the species invest in body size, the more the males of the same species invest in the exacerbation of reproductionrelated phenotypic traits. In the case of head size, this may be related to a large head providing males with increased bite force, and therefore during intersexual interactions (i.e., courtship, copulation), males may benefit from increased bite performance, because they will be able to grasp larger females to copulate $[15,18]$.

In relation to fecundity selection, in the Chaco Domain the macroevolutionary morphological responses are not allometric in all the reproduction-related phenotypic traits but evolutionary responses may also be diverse in the different traits, for instance, being more accented in some traits, such as ITL, which is directly related to fecundity. We found no support for the exacerbation of abdominal width and tail perimeter associated with SSD, indicating that evolutionary changes in SSD in female body size may not be associated with evolutionary changes in abdominal capacity or with energy reserves related to tail size. However, we found support for the fecundity selection in that, in female-biased SSD species, the more the females invest in body size; the more they also invest in the exacerbation of ITL. When females are the larger sex, this is most commonly explained by fecundity selection acting to increase abdomen length [8].

Our macroevolutionary comparison across taxa also suggests that the selection of fecundity has had a major role in the evolution of female body shape by enlarging the abdomen and thus favoring clutch/litter size. Our results (Table 3) strongly indicate that the evolution of a large abdomen (ITL) allows females to accommodate

Table 4 Phylogenetic generalized least squares evaluating the effect of residual SSD on residual ITL considering reproductive mode

\begin{tabular}{llcllll}
\hline Model & $\lambda$ & Adj. r 2 & Factor Levels & Slope & SE & $P$ \\
\hline Residual ITL $~$ & 0.000 & 0.946 & Oviparous & 0.972 & 0.045 & $<0.001$ \\
Residual SSD & & & Viviparous & 0.869 & 0.079 & 0.313 \\
\hline
\end{tabular}

$\lambda$ phylogenetic signal (Pagel's), $r 2$ correlation coefficient, SE standard error more offspring. The abdomen limits physically the maternal allocation in the offspring; therefore abdomen size is under direct selection pressure $[2,8,69,75]$. Actually, in lizards, when the abdomen is experimentally reduced, also clutch size decreases [76], this is because the strong correlation between the abdomen size and the clutch size $[15,70,77,78]$. Our results complement those of Cox et al. [8] who demonstrated that SSD is positively correlated with clutch/litter size, but we found that, from a macroevolutionary perspective, ITL is a major trait involved in enabling increased clutch/litter size, similar to the findings of [36].

With respect to reproductive mode, we showed that the outcomes of evolutionary processes related to changes in sexual dimorphism differed according to reproductive modes; i.e., only oviparous species there is a relationship between residual SSD and residual ITL. Moreover, these parameter and clutch/litter sizes were interrelated, only oviparous species. This may indicate the importance of abdominal length for storing many eggs, although the development of those eggs would require less abdominal space in oviparous than in viviparous species. These results do not match our prediction. It would be expected that females of viviparous species would be larger than those of oviparous species, generating more female-biased patterns of SSD, but we found only a minimal tendency to divert towards female-biased SSD. However, viviparous species may be affected by fecundity selection through another reproductive parameter which we did not consider in this work (e.g., relative clutch/litter mass of the eggs, clutch/ litter frequency, progeny size; see $[79,80])$. As stated by Kupfer et al. [81] reproductive traits are likely to change in an evolutionary scenario of reproductive modes, in fact they evaluated several traits related to female investment and female size and found that variables such as hatchling size, egg volume and offspring number were influenced by the evolution of reproductive modes.

Integrated analyses across biological and evolutionary scales will serve to solidify the synthesis of evolutionary biology and shed new light on SSD patterns from a macroevolutionary perspective. Estimation of the phylogenetic signal $(\lambda)$ is very valuable for elucidating the imprint of phylogeny on the body shape of relative species. In most associations between reproduction-related phenotypic traits (such as IHW, IHH, ILH, ITP male and ITL) and SSD, we found a low phylogenetic signal, 
Table 5 Phylogenetic generalized least squares evaluating the effect of residuals ITL on fecundity considering to reproductive mode

\begin{tabular}{llcllll}
\hline Model & $\lambda$ & Adj. $^{2}$ & Factor Levels & Slope & SE & $P$ \\
\hline $\begin{array}{l}\text { Residual Clutch/ } \\
\text { litter size } \sim\end{array}$ & 1.000 & 0.765 & Oviparous & 1.599 & 0.275 & $<0.001$ \\
Residual ITL & & & & & & \\
\hline
\end{tabular}

$\lambda$ phylogenetic signal (Pagel's), $r^{2}$ correlation coefficient, SE standard error

which may indicate that, beyond phylogeny, the evolutionary dynamic influences both SSD and reproduction-related phenotypic traits. In contrast, the high phylogenetic signal observed in other models where reproduction-related phenotypic traits (such as IAW, ITP female) were not associated with SSD suggests that evolutionary processes related to sexual dimorphism may influence body size differently from other phenotypic traits. Reproduction-related phenotypic traits may be under different selection pressures resulting in a diversity of patterns of sexual dimorphism of the body parts.

\section{Conclusions}

Our study on SSD patterns of lizards of the Chaco Domain from a macroevolutionary perspective included a large number of diverse genera and families, and demonstrated the high diversity of SSD patterns, which might be related to a great diversity of reproductive strategies of the lizards inhabiting in this region. The sexual selection may have acted on whole-body size as well as on the size of body parts related to reproduction. Male and female phenotypes evolutionarily respond to variations in SSD, and an understanding of these patterns is essential for elucidating the processes shaping sexual phenotype diversity from a macroevolutionary perspective.

\section{Abbreviations \\ AW: Abdominal width; HH: Head height; HW: Head width; LH: Total length of hindlimb; PGLS: Phylogenetic Generalized Least Squares; SSD: Sexual size dimorphism; SVL: Snout-vent length; TL: Trunk length; TP female: Female tail perimeter; TP male: Male tail perimeter}

\section{Acknowledgments}

We are grateful to Mario Cabrera, Nicolas Pelegrin and Sergio Naretto for allowing us to review their personal collection, to Sonia Kretzschmar, Demian Slodki and Santiago Nenda, the curators of museums, for help in organizing the material, and to Maximiliano Tourmente and Lina Moreno Azócar for help with phylogeny and comparative methods. We thank two anonymous reviewers for their constructive feedback on the manuscript.

\section{Funding}

This study was funded by the Consejo Nacional de Investigaciones Científicas y Técnicas CONICET PIP 2011-2013; CONICET PIP 2015-2017; Fondo para la Investigación Científica y Tecnológica (FONCYT) PICT-20111599 Res 140/12; PICT-BICENTARIO Nro. 2010-2782, PICT-E (IDEA-CONICET) N ${ }^{\circ} 2014-0062$. The funders had no role in the design of the study, collection, analysis and interpretation of data neither in the writing of the manuscript.

\section{Availability of data and materials}

The datasets used and/or analysed during the current study are available from the corresponding author on reasonable request.

\section{Authors' contributions}

GLJ, MC and GC conceived the study and wrote the paper. GLJ collected and analyzed the data. All authors have read and approved the manuscript.

Ethics approval and consent to participate

Not applicable.

Consent for publication

Not applicable.

Competing interests

The authors declare that they have no competing interests.

\section{Publisher's Note}

Springer Nature remains neutral with regard to jurisdictional claims in published maps and institutional affiliations.

Received: 4 September 2018 Accepted: 19 November 2018

Published online: 07 December 2018

\section{References}

1. Jiménez-Arcos VH, Sanabria-Urbán S, Cueva del Castillo R. The interplay between natural and sexual selection in the evolution of sexual size dimorphism in Sceloporus lizards (Squamata: Phrynosomatidae). Ecol Evol. 2017:7:905-17.

2. Blanckenhorn WUW. Behavioral causes and consequences of sexual size dimorphism. Ethology. 2005;111:977-1016.

3. Fairbairn DJ, Blanckenhorn WU, Székely T. Sex, size \& gender roles Evolutionary studies of sexual size dimorphism. Oxford: Oxford University Press; 2007.

4. Fairbairn DJ. Allometry for sexual size dimorphism: pattern and process in the coevolution of body size in males and females. Annu Rev Ecol Syst. 1997;28:659-87

5. Rensch B. Die Abhängigkeit der relativen Sexual-differenz von der Körpergrösse. Bonn Zool Beiträge. 1950;1:58-69.

6. Zug GR, Balazs GH, Wetherall JA, Parker DM, Murakawa SKK. Age and growth of Hawaiian green seaturtles (Chelonia mydas): an analysis based on skeletochronology. Fish B-Noaa. 2001;100:117-27.

7. Madsen T, Shine R. Silver spoons and snake body sizes: prey availability early in life influences long-term growth rates of free-ranging pythons. J Anim Ecol. 2000;69:952-8.

8. Cox RM, Skelly SL, John-Alder HB. A comparative test of adaptive hypotheses for sexual size dimorphism in lizards. Evolution. 2003:57:1653-69.

9. Gienger CM, Beck DD. Heads or tails? Sexual dimorphism in helodermatid lizards. Can J Zool. 2007:85:92-8.

10. Butler MA, Losos JB. Multivariate sexual dimorphism, sexual selection, and adaptation in greater antillean Anolis lizards. Ecol Monogr. 2002;72:541-59.

11. Kratochvil L, Fokt M, Rehák I, Frinta D. Misinterpretation of character scaling: a tale of sexual dimorphism in body shape of common lizards. Can J Zool. 2003:81:1112-7.

12. Kaliontzopoulou A, Carretero MA, Adams DC. Ecomorphological variation in male and female wall lizards and the macroevolution of sexual dimorphism in relation to habitat use. J Evolution Biol. 2015;28:80-94.

13. Andersson M. Sexual selection. Princeton: Princeton University Press; 1994.

14. Cardozo G, Naretto S, Blengini CS, Chiaraviglio M. Phenotypic diversity in female body shape is related to reproductive potential in Tupinambis merianae lizards. Ann Zool Fenn. 2015;52:129-44.

15. Gvozdik L, Van Damme R. Evolutionary maintenance of sexual dimorphism in head size in the lizard Zootoca vivipara: a test of two hypotheses. J Zool. 2003;259:7-13

16. Herrel A, Andrade DV, de Carvalho JE, Brito A, Abe A, Navas C. Aggressive behavior and performance in the tegu lizard Tupinambis merianae. Physiol Biochem Zool. 2009;82:680-5.

17. Vanhooydonck B, Cruz FB, Abdala CS, Azócar DLM, Bonino MF, Herrel A. Sex-specific evolution of bite performance in Liolaemus lizards (Iguania: Liolaemidae): the battle of the sexes. Biol J Linn Soc. 2010;101:461-75. 
18. Naretto S, Cardozo G, Blengini CS, Chiaraviglio M. Sexual selection and dynamics of jaw muscle in Tupinambis lizards. Evol Biol. 2014;41:192-200.

19. Vanhooydonck B, Van Damme R, Aerts P. Speed and stamina trade-off in lacertid lizards. Evolution. 2001;55:1040-8.

20. Fox SF, JK MC, Baird TA. The evolutionary study of social behavior and the role of lizards as model organisms. In: Fox SF, JK MC, Baird TA, editors. Lizard social behavior. Baltimore: John Hopkins University Press; 2003. p. xi-xiv.

21. Husak JF, Fox SF, Lovern MB, Van Den Bussche RA. Faster lizards sire more offspring: sexual selection on whole-animal performance. Evolution. 2006;60:2122-30.

22. Herrel A, Spithoven L, Van Damme R, De Vree F. Sexual dimorphism of head size in Gallotia galloti: testing the niche divergence hypothesis by functional analyses. Funct Ecol. 1999;13:289-97.

23. Vitt $L$, Cooper WE Jr. The evolution of sexual dimorphism in the skink Eumeces laticeps: an example of sexual selection. Can J Zool. 1985;63:995-1002.

24. Bull CM, Pamula Y. Sexually dimorphic head sizes and reproductive success in the sleepy lizard Tiliqua rugosa. J Zool. 1996:240:511-21.

25. Costa HC, Silva ET, Campos PS, Oliveira MPC, Nunes AV, Campos PS. The corpse bride: a case of Davian behavior in the green Ameiva (Ameiva ameiva) in southeastern Brazil. Herpetol Notes. 2010;3:79-83.

26. Ribeiro LB, Gogliath M, Sales RFDD, Freire EMX. Mating behavior and female accompaniment in the whiptail lizard Cnemidophorus ocellifer (Squamata, Teiidae) in the Caatinga region of northeastern Brazil. Biota Neotrop. 2011;11:363-8.

27. Martín J, Salvador A. Effects of tail loss on the time-budgets, movements, and spacing patterns of Iberian rock lizards, Lacerta monticola. Herpetologica. 1997;53:117-25.

28. Salvador A, Martin J, López P. Tail loss reduces home range size and access to females in male lizards, Psammodromus algirus. Behav Ecol. 1995;6:382-7.

29. Salvador A, Martín J, López P, Veiga JP. Long-term effect of tail loss on home-range size and access to females in male lizards (Psammodromus algirus). Copeia. 1996;1:208-9.

30. Angilletta MJ. Estimating and comparing thermal performance curves. J Therm Biol. 2006:31:541-5.

31. Lourdais $O$, Shine R, Bonnet X, Brichoux F. Sex differences in body composition, performance and behaviour in the Columbian rainbow boa (Epicrates cenchria maurus, Boidae). J Zool. 2006;269:175-82.

32. Du W, Lu D. An experimental test of body volume constraint on female reproductive output. J Exp Zool. 2010;313:123-8.

33. Olsson M, Shine R, Wapstra E, Ujvari B, Madsen T. Sexual dimorphism in lizard body shape: the roles of sexual selection and fecundity selection. Evolution. 2002;56:1538-42.

34. Kaliontzopoulou A, Carretero MA, Llorente GA. Multivariate and geometric morphometrics in the analysis of sexual dimorphism variation in Podarcis lizards. J Morphol. 2007;268:152-65.

35. Boretto JM, Ibargüengoytía NR. Phymaturus of Patagonia, Argentina: reproductive biology of Phymaturus zapalensis (Liolaemidae) and a comparison of sexual dimorphism within the genus. J Herpetol. 2009;43:96-104.

36. Scharf I, Meiri S. Sexual dimorphism of heads and abdomens: different approaches to "being large" in female and male lizards. Biol J Linn Soc. 2013;110:665-73

37. Braña F. Sexual dimorphism in lacertid lizards: male head increase vs female abdomen increase? Oikos. 1996;75:511-23.

38. Yan-Yan S, Du Y, Yang J, Fu TB, Lin CX, Ji X. Is the evolution of viviparity accompanied by a relative increase in maternal abdomen size in lizards? Evol Biol. 2012;39:388-99.

39. Stewart JR, Blackburn DG. Viviparity and placentation in lizards. In: Rheubert $J$, Siegel DS, Trauth SE, editors. Reproductive biology and phylogeny of lizards and tuatara. Boca Raton: CRC Press; 2014. p. 448-563.

40. Pincheira-Donoso D, Tregenza T. Fecundity selection and the evolution of reproductive output and sex-specific body size in the Liolaemus lizard adaptive radiation. Evol Biol. 2011:38:197-207.

41. Qualls CP, Shine R. Maternal body-volume as a constraint on reproductive output in lizards: evidence from the evolution of viviparity. Oecologia. 1995;103:73-8.

42. Morrone JJ. Biogeografía de América Latina y el Caribe. Manuales y Tesis SEA 3. Zaragoza (España). 2001.

43. Morrone JJ. Panbiogeografía, componentes bióticos y zonas de transición. Rev Bras Entomol. 2004;48:149-62.

44. Cardozo G, Rivera PC, Lamfri M, Scavuzzo M, Gardenal C, Chiaraviglio M. Effects of habitat loss on the genetic structure of the Argentine Boa
Constrictor (Boa constrictor occidentalis) populations. In: Henderson R, Powell R, editors. Biology of the Boa and Phytons. Eagle Mountain publishing: Utah; 2007. p. 329-38

45. Cardozo G, Chiaraviglio M. Landscape changes influence the reproductive behaviour of a key 'capital breeder'snake (Boa constrictor occidentalis) in the Gran Chaco region, Argentina. Biol Conserv. 2008;141:3050-8.

46. Pelegrin N, Bucher EH. Activity and reproductive patterns of lizards in the Chaco of Argentina. J Nat Hist. 2015;49:2693-708.

47. Nori J, Torres R, Lescano JN, Cordier JM, Periago ME, Baldo D. Protected areas and spatial conservation priorities for endemic vertebrates of the Gran Chaco, one of the most threatened ecoregions of the world. Divers Distrib. 2016;22:1212-9.

48. The Nature Conservancy (TNC), Fundación Vida Silvestre Argentina (FVSA), Fundación para el Desarrollo Sustentable del Chaco (DeSdel Chaco) y Wildife Conservation Society Bolivia (WCS). Evaluación Ecorregional del Gran Chaco Americano / Gran Chaco Americano Ecoregional Assessment. Buenos Aires: Fundación Vida Silvestre Argentina; 2005.

49. Szumik C, Aagesen L, Casagranda D, et al. Detecting areas of endemism with a taxonomically diverse data set: plants, mammals, reptiles, amphibians, birds, and insects from Argentina. Cladistics. 2012;28:317-29.

50. Cabrera MP, Scrocchi GJ, Cruz FB. Sexual size dimorphism and allometry in Liolaemus of the L. laurenti group (Sauria: Liolaemidae): morphologic lability in a clade of lizards with different reproductive modes. Zool Anz. 2013;252:299-306.

51. Bertona M, Chiaraviglio M. Reproductive biology, mating aggregations, and sexual dimorphism of the argentine Boa constrictor (Boa constrictor occidentalis). J Herpetol. 2003;37:510-6.

52. Boretto JM, Ibargüengoytía NR. Asynchronous spermatogenesis and biennial female cycle of the viviparous lizard Phymaturus antofagastensis (Liolaemidae): reproductive responses to high altitudes and temperate climate of Catamarca, Argentina. Amphibia-Reptilia. 2006;27:25-36.

53. Abdala V, Manzano A, Nieto L, Diogo R. Comparative myology of Leiosauridae (Squamata) and its bearing on their phylogenetic relationships. Belg J Zool. 2009:139:109.

54. Harvey MB, Ugueto GN, Gutberlet RL Jr. Review of teiid morphology with a revised taxonomy and phylogeny of the Teiidae (Lepidosauria: Squamata). Zootaxa. 2012;3459:156.

55. Lobo F, Nenda SJ. Discovery of two new species of Phymaturus (Iguania: Liolaemidae) from Patagonia, Argentina, and occurrence of melanism in the patagonicus group. Cuad Herpetol. 2015;29:5-25.

56. Lobo F, Barrasso DA, Hibbard T, Basso NG. On the evolution and diversification of an Andean clade of reptiles: combining morphology and DNA sequences of the palluma group (Liolaemidae: Phymaturus). Zool J Linn Soc-Lond. 2016;176:648-73.

57. Pyron RA, Burbrink FT, Wiens JJ. A phylogeny and revised classification of Squamata, including 4161 species of lizards and snakes. BMC Evol Biol. 2013;13:93

58. Felsenstein J. Confidence limits on phylogenies: an approach using the bootstrap. Evolution. 1985:39:783-91.

59. Lovich JE, Gibbons JW. A review of techniques for quantifying sexual size dimorphism. Growth Dev Aging. 1992;56:269.

60. Butler MA, Schoener TW, Losos JB. The relationship between sexual size dimorphism and habitat use in greater Antillean Anolis lizards. Evolution. 2000:54:259-72.

61. Losos JB, Butler M, Schoener TW. Sexual dimorphism in body size and shape in relation to habitat use among species of Caribbean Anolis lizards. In: Fox SF, McCoy JK, Baird TA, editors. Lizard social behaviour. Baltimore: John Hopkins University Press; 2003. p. 356-80.

62. Harvey PH, Pagel M.D. The comparative method in evolutionary biology. Oxford: Oxford university press; 1991

63. Tulli MJ, Cruz FB, Kohlsdorf T, Abdala V. When a general morphology allows many habitat uses. Integr Zool. 2016;11:483-99.

64. Revell LJ. Phytools: an R package for phylogenetic comparative biology (and other things). Methods Ecol Evol. 2012:3:217-23.

65. Orme CDL, Freckleton RP, Thomas GH, Petzoldt T, Fritz SA, NJB I. CAPER: Comparative analyses of phylogenetics and evolution in R. Methods Ecol Evol. 2012;3:145-51.

66. Paradis E, Claude J, Strimmer K. APE: analyses of phylogenetics and evolution in R language. Bioinformatics. 2004;20:289-90.

67. R Development Core Team. R: a language and environment for statistical computing. Vienna: R Foundation for Statistical Computing; 2018. 
68. Cox RM, Butler MA, John-Alder HB. The evolution of sexual size dimorphism in reptiles. In: Fairbairn DJ, Blanckenhorn WU, Székely T, editors. Sex, size and gender roles: evolutionary studies of sexual size dimorphism. London: Oxford University Press; 2007. p. 38-49.

69. Stuart-Fox D. A test of Rensch's rule in dwarf chameleons (Bradypodion spp.), a group with female-biased sexual size dimorphism. Evol Ecol. 2009;23:425-33.

70. Anderson RA, Vitt LJ. Sexual selection versus alternative causes of sexual dimorphism in teiid lizards. Oecologia. 1990;84:145-57.

71. Haenel GJ, Smith LC, John-Alder H. Home-range analysis in Sceloporus undulatus. II. A test of spatial relationships and reproductive success. Copeia. 2003;1:113-23.

72. Kratochvíl L, Frynta D. Body size, male combat and the evolution of sexual dimorphism in eublepharid geckos (Squamata: Eublepharidae). Biol J Linn Soc. 2002;76:303-14.

73. Reaney LT, Whiting MJ. Life on a limb: ecology of the tree agama (Acanthocercus a. atricollis) in southern Africa. J Zool. 2002;257:439-48.

74. Lailvaux SP, Irschick DJ. The evolution of performance-based male fighting ability in Caribbean Anolis lizards. Am Nat. 2007;170:573-86.

75. Zamudio KR. The evolution of female-biased sexual size dimorphism: a population-level comparative study in horned lizards (Phrynosoma). Evolution. 1998:52:1821-33.

76. Du W, Ji X, Shine R. Does body-volume constrain reproductive output in lizards? Biol Lett. 2005;1:98-100

77. Shine R. Ecological causes for the evolution of sexual dimorphism: a review of the evidence. O Rev Biol. 1989:64:419-61.

78. Shine R, Greer AE. Why are clutch sizes more variable in some species than in others? Evolution. 1991;45:1696-706.

79. Vitt $L$, Price $H J$. Ecological and evolutionary determinants of relative clutch mass in lizards. Herpetologica. 1982;38:237-55.

80. Pianka ER, Vitt LJ, Pelegrin N, Fitzgerald DB, Winemiller KO. Toward a periodic table of niches, or exploring the lizard niche hypervolume. Am Nat. 2017:190:601-16

81. Kupfer A, Maxwell E, Reinhard S, Kuehnel S. The evolution of parental investment in caecilian amphibians: a comparative approach. Biol J Linn Soc. 2016;119:4-14.

82. Corl A, Davis AR, Kuchta SR, Comendant T, Sinervo B. Alternative mating strategies and the evolution of sexual size dimorphism in the side-blotched lizard, Uta stansburiana: a population-level comparative analysis. Evolution. 2009;64:79-96.

Ready to submit your research? Choose BMC and benefit from:

- fast, convenient online submission

- thorough peer review by experienced researchers in your field

- rapid publication on acceptance

- support for research data, including large and complex data types

- gold Open Access which fosters wider collaboration and increased citations

- maximum visibility for your research: over $100 \mathrm{M}$ website views per year

At $\mathrm{BMC}$, research is always in progress.

Learn more biomedcentral.com/submissions 